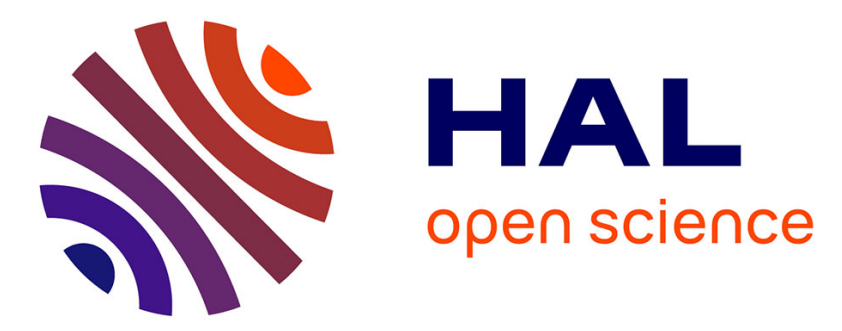

\title{
Large tectonic earthquakes induce sharp temporary decreases in seismic velocity in Volcán de Colima, Mexico
}

\author{
Philippe Lesage, G. Reyes-Dávila, R. Arámbula-Mendoza
}

\section{To cite this version:}

Philippe Lesage, G. Reyes-Dávila, R. Arámbula-Mendoza. Large tectonic earthquakes induce sharp temporary decreases in seismic velocity in Volcán de Colima, Mexico. Journal of Geophysical Research, 2014, 119, pp.4360-4376. 10.1002/2013JB010884 . hal-01022860

\section{HAL Id: hal-01022860 \\ https://hal.univ-grenoble-alpes.fr/hal-01022860}

Submitted on 15 Jul 2014

HAL is a multi-disciplinary open access archive for the deposit and dissemination of scientific research documents, whether they are published or not. The documents may come from teaching and research institutions in France or abroad, or from public or private research centers.
L'archive ouverte pluridisciplinaire HAL, est destinée au dépôt et à la diffusion de documents scientifiques de niveau recherche, publiés ou non, émanant des établissements d'enseignement et de recherche français ou étrangers, des laboratoires publics ou privés. 


\section{QAGUPUBLICATIONS}

\section{Journal of Geophysical Research: Solid Earth}

\section{RESEARCH ARTICLE \\ 10.1002/2013JB010884 \\ Key Points: \\ Large tectonic earthquakes induce sharp temporary decreases in seismic velocity in Volcán de Colima, Mexico}

- Variations in seismic velocity were calculated at Volcan de Colima over 15 years

- Earthquakes induced sharp velocity decreases in the shallow part of the volcano

- Decreases are interpreted as being due to material softening caused by shaking

Correspondence to:

P. Lesage,

lesage@univ-savoie.fr

\section{Citation:}

Lesage, P., G. Reyes-Dávila, and R. Arámbula-Mendoza (2014), Large tectonic earthquakes induce sharp temporary decreases in seismic velocity in Volcán de Colima, Mexico, J. Geophys. Res. Solid Earth, 119, 4360-4376, doi:10.1002/ $2013 J B 010884$.

Received 2 DEC 2013 Accepted 21 APR 2014 Accepted article online 24 APR 2014 Published online 21 MAY 2014

\author{
Philippe Lesage ${ }^{1,2}$, Gabriel Reyes-Dávila ${ }^{3}$, and Raúl Arámbula-Mendoza ${ }^{3}$ \\ ${ }^{1}$ ISTerre, Université de Savoie, Le Bourget-du-Lac, France, ${ }^{2}$ ISTerre, CNRS, Le Bourget-du-Lac, France, ${ }^{3}$ Centro Universitario \\ de Estudios e Investigaciones en Vulcanología, Colima, Mexico
}

\begin{abstract}
We used the ambient noise cross-correlation and stretching methods to calculate variations in seismic velocities in the region of Volcán de Colima, Mexico. More than 15 years of continuous records were processed, producing long time series of velocity variations related to volcanic activity, meteorological effects, and earthquakes. Velocity variations associated with eruptive activity are tenuous, which probably reflects the open state of the volcano during the study period. Fifteen events among 26 regional tectonic earthquakes produced sharp, temporary decreases in seismic velocities, which then recovered progressively following a linear trend as a function of the logarithm of time. For the 15 events, the amplitude of the perturbation increased almost linearly with the logarithm of the amplitude of the seismic waves that shook the edifice. The most dramatic apparent velocity variation was a drop of up to $2.6 \%$ during the nearby $M 7.4$ Tecomán earthquake in 2003. In order to locate the perturbation in the horizontal plane we applied an inverse method based on the radiative transfer approximation. We also used an original approach based on the frequency dependence of velocity variations to estimate the depth of the perturbation. Our results show that the velocity variation was well localized in the shallow layers $(<800 \mathrm{~m})$ of the volcano, with almost no variations occurring outside the edifice. We discuss several possible interpretations and conclude that the most plausible explanation for the velocity decreases is the nonlinear elastic behavior of the granular volcanic material and its mechanical softening induced by transient strains.
\end{abstract}

\section{Introduction}

The quest to improve eruption forecasting requires detailed studies of phenomena that accompany volcanic unrest and comprehensive knowledge of volcanoes' responses to external forcing. Hence, it is necessary to detect and analyze a maximum number of precursors, develop new approaches, and test their predictive potential at many volcanoes. It is also important to identify the origins of different phenomena and to separate processes that originate directly in magmatic or hydrothermal systems from those due to external causes such as tectonic earthquakes.

The most striking effect of large tectonic earthquakes on volcanoes is the triggering of eruptions. Many cases have been reported, including Santa Maria volcano, Guatemala, in 1902 [Rockstroh, 1902], Cordon Caulle, Chile, in 1960 [Lara et al., 2004], and Kilauea, Hawaii, in 1975 [Lipman et al., 1985]. Statistical studies of seismic and eruptive catalogues have shown that the number of eruptions during the few days following a large earthquake is much greater than would be expected [Linde and Sacks, 1998; Marzocchi, 2002]. Several processes that enhance small static stress variations or that convert transient strains into permanent pressure changes have been proposed to explain these observations [Manga and Brodsky, 2006; Walter, 2007]. However, most large earthquakes do not trigger eruptions of either nearby or distant volcanoes; a more frequent phenomenon is an increase in volcano seismicity after an earthquake. One well-studied case is seismic activity at Long Valley Caldera, which increased after several large events in California and Alaska [Hill et al., 1995; Gomberg et al., 2001; Prejean et al., 2004]. Swarms of microearthquakes have also been observed during the passing of surface waves from teleseismic events [West et al., 2005]. Conversely, the shaking of a volcano may result in a clear decline in its seismic activity, as occurred at Mount Wrangell volcano, Alaska, after the nearby 2002 Denali earthquake [Sanchez and McNutt, 2004].

Volcanoes' responses to earthquakes also include a wide variety of other phenomena, including changes in degassing [Cigolini et al., 2007], extrusion rate [Walter et al., 2007], and volcanic tremor activity [Moran et al., 2004], 
increases in crater lake level [Barquero et al., 1995], subsidence [Takada and Fukushima, 2013; Pritchard et al., 2013], and velocity variations in the structure. In 1998, a 0.3 to $1 \%$ decrease in seismic velocity was detected at Mount Iwate, Japan, related to a M6.1 earthquake that occurred close to the volcano [Nishimura et al., 2000, 2005]. Recently, a velocity drop followed by a slow recovery was observed at Yasur volcano, Vanuatu, after a M7.3 earthquake $80 \mathrm{~km}$ from the crater [Battaglia et al., 2012]. Velocity changes caused by earthquakes have been extensively studied in various parts of the San Andreas Fault system [Poupinet et al., 1984; Schaff and Beroza, 2004; Rubinstein and Beroza, 2004; Brenguier et al., 2011], close to the North Anatolian fault [Peng and Ben-Zion, 2006], and in the regions of the 2003 Tokachi-Oki and the 2011 Tohoku-Oki earthquakes [Rubinstein et al., 2007; Nakata and Snieder, 2011; Minato et al., 2012].

Temporal changes in seismic velocity related to eruptive activity or external forcing have also been measured in a few volcanoes. A velocity increase of up to $1.2 \%$ was detected during the 4 months preceding the 1991 eruption of Merapi volcano, Indonesia. This increase has been attributed to the closing of cracks in the vicinity of the magma chamber or conduit due to a pressure increase [Ratdomopurbo and Poupinet, 1995]. A similar phenomenon occurred before the 1998 eruption of Merapi [Wegler et al., 2006]. Noise correlation and multiplet approaches revealed a more complex pattern of velocity variations before the large explosive eruption of Merapi in 2010 [Budi-Santoso, 2014]. However, part of the velocity variations in Merapi may also be related to changes in groundwater level between the dry and wet seasons [Sens-Schönfelder and Wegler, 2006]. At Piton de la Fournaise volcano, Reunion Island, continuous monitoring of the seismic velocity has revealed velocity decreases of the order of $0.05 \%$ a few weeks before eruptions [Brenguier et al., 2008]. The dike intrusion and caldera formation at Miyakejima volcano, Japan, in 2000 was accompanied by a velocity increase of up to $3.3 \%$ on the flanks of the edifice and a velocity decrease of up to $2.3 \%$ in regions close to the caldera. These complex velocity changes may have been caused by a combination of deflation sources and topographic changes [Anggono et al., 2012]. A temporary decrease of $0.8 \%$ of the seismic velocity was also observed starting 2 days before a phreatic eruption of Mount Ruapehu, New Zealand, in 2006 [Mordret et al., 2010].

In all the above examples, the velocity variations were calculated by comparing seismograms with similar waveforms obtained at different dates. These signals come from either repeating seismic events (multiplets [Poupinet et al., 1984; Ratdomopurbo and Poupinet, 1995; Grêt et al., 2005; Schaff and Beroza, 2004; Rubinstein et al., 2007; Battaglia et al., 2012] or artificial, controlled seismic sources [Wegler et al., 2006; Nishimura et al., $2000,2005])$ or they are obtained by the recently developed ambient seismic noise cross-correlation method [Sens-Schönfelder and Wegler, 2006; Brenguier et al., 2008; Anggono et al., 2012; Obermann et al., 2013b]. When velocity changes occur in the medium during the interval between two similar records, they produce delays in the arrival of seismic waves that accumulate with time in seismograms, especially in the coda. These delays can be measured in the time domain, via cross-correlation [Wegler et al., 2006; Rubinstein et al., 2007; Battaglia et al., 2012; Anggono et al., 2012] or the stretching method [Lobkis and Weaver, 2003; Sens-Schönfelder and Wegler, 2006], or in the frequency domain, using the cross-spectral method [Poupinet et al., 1984; Ratdomopurbo and Poupinet, 1995; Nishimura et al., 2000, 2005; Brenguier et al., 2008; Clarke et al., 2011].

Up to now, this approach has been applied to only a small number of volcanoes and, in most cases, to relatively short time series. Hence, studies of new cases that include several eruptive and seismic episodes are needed in order to improve knowledge and understanding of velocity variations in volcanoes. In the present research, analyses of velocity variations in Volcán de Colima over a period of 15 years allowed us to identify several phenomena that generate velocity changes of different amplitudes and durations and that are associated with either eruptive activity or external forcing.

\section{Geological Setting and Seismic Network}

Volcán de Colima is Mexico's most active volcano [Medina-Martínez, 1983; Luhr and Carmichael, 1990]. It is located in the western part of the Trans-Mexican Volcanic Belt, close to where the Cocos and Rivera plates are subducted under the North American plate (Figure 1a). The approximately $3000 \mathrm{~m}$ thick volcanic pile overlies an $\sim 1000$ m thick layer of quaternary sediments that fills the Colima graben and a basement of Cretaceous limestone and intrusive rocks [Norini et al., 2010]. Large Plinian eruptions occurred in 1818 and 1913 [De la Cruz-Reyna, 1993], and several episodes of eruptive activity, characterized by the extrusion of lava domes, lava flows, rock falls, pyroclastic flows, and vulcanian explosions, have taken place since the 1990s. The last explosive activity occurred in 2004-2005 [Arámbula-Mendoza et al., 2011]. An extrusive episode began in January 2013 and was still continuing 1 year later. A seismic monitoring system has been operating on the 


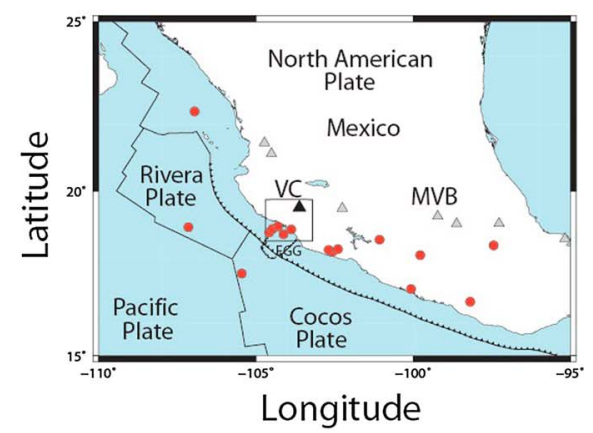

a)

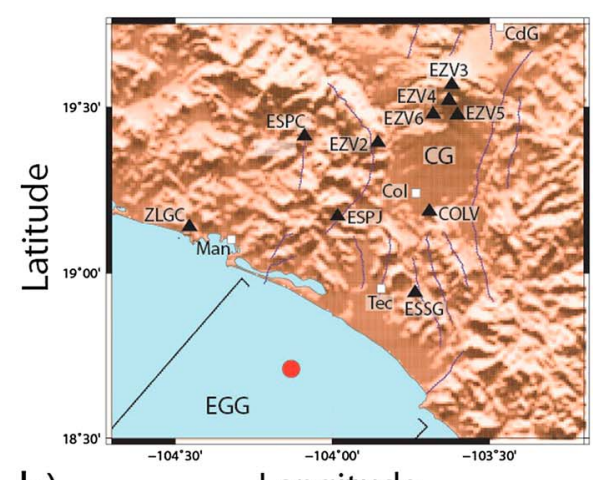

b)

Longitude

Figure 1. Maps of the study area. (a) Tectonic setting of Volcán de Colima (VC). Red dots are the epicenters of tectonic earthquakes that induced velocity changes in the volcano. EGG: El Gordo Graben. MVB: Mexican Volcanic Belt. The box indicates the area shown in Figure 1b. (b) Map of the RESCO seismic network (black triangles), showing main towns and cities (Col: Colima City, Man: Manzanillo, Tec: Tecomán, and CdG: Ciudad Guzmán). Red circle: epicenter of the 22 January 2003, M7.4 Tecomán earthquake. Blue lines: normal faults associated with the Colima Graben (CG).

volcano for more than 20 years as part of the State of Colima's Seismological Network (RESCO). This network includes four short-period vertical seismometers on the edifice, together with six other stations nearer to the coast that were installed to study tectonic earthquakes (Figure 1b). The first broadband sensor was installed close to station EZV5 in 2001, and others were set up in 2007 and 2008. The continuous recordings made since March 1998 have allowed seismic noise to be processed.

\section{Extraction of Green Functions and Estimation of Apparent Velocity Variations}

\subsection{Methods}

Theoretical and experimental studies have shown that the impulse responses of a medium between two sites, known as Green functions, can be extracted by cross-correlating diffuse wavefields recorded at these points [e.g., Weaver and Lobkis, 2001; Campillo and Paul, 2003]. Hence, it is possible to reconstruct seismogram-like functions that are regularly spaced in time by cross-correlating ambient seismic noise. Comparing these series of correlation functions, it is then possible to detect slight temporal modifications in the medium [Brenguier et al., 2008].



Figure 2. Cross-correlation functions of ambient seismic noise for some pairs of stations, displayed as a function of interstation distance. The frequency interval used for the calculations is $[0.125-2] \mathrm{Hz}$. The waveforms are more complex and their codas longer for station pairs in which at least one of the stations is on the volcanic structure (EZV3 to EZV6). 


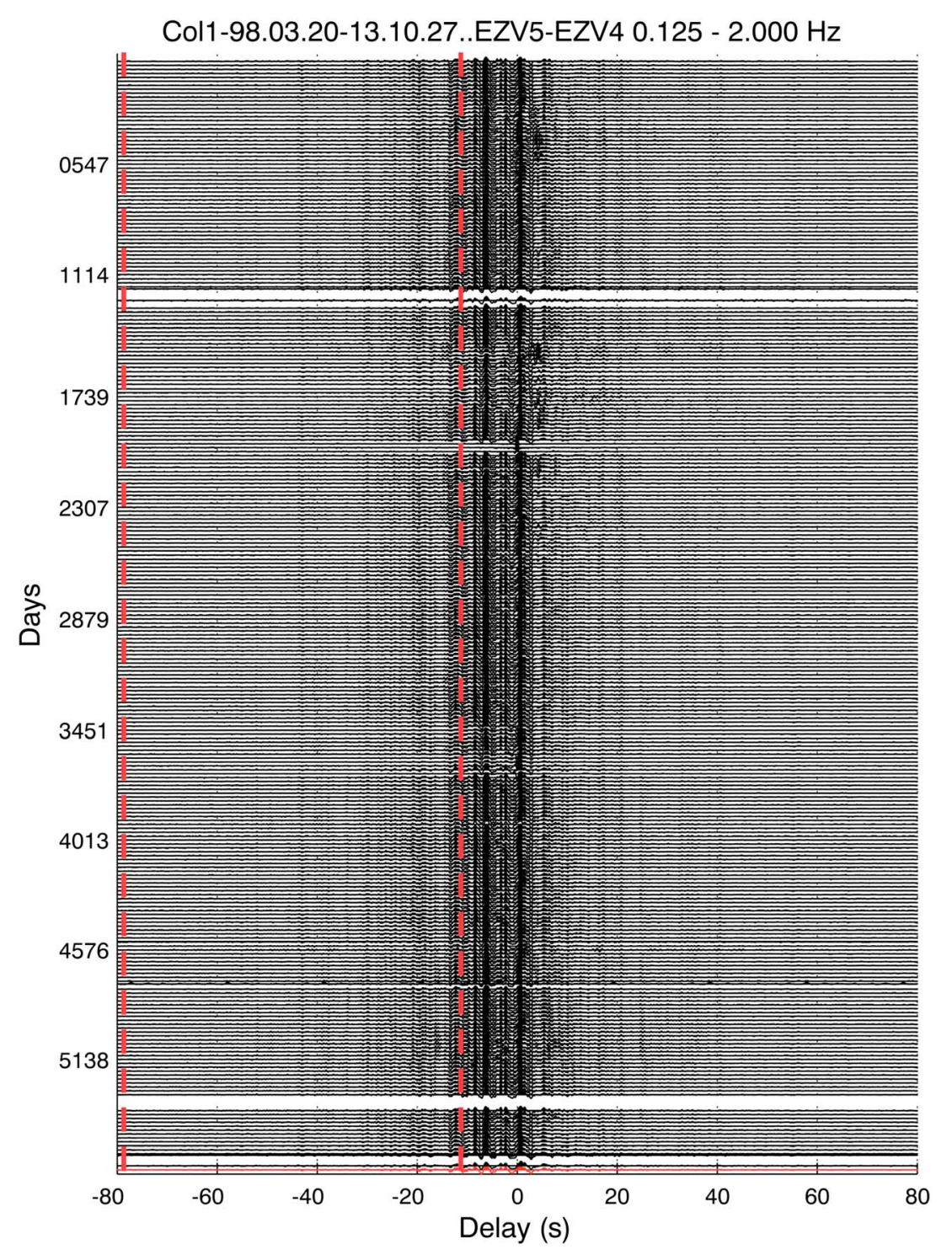

Figure 3. Cross-correlation functions for the pair EZV5-EZV4 calculated for 20 day contiguous intervals over 15 years. Vertical, dashed red lines show the delay window used for most calculations. Stability was good for almost all the study period.

In the present research we processed continuous recordings from RESCO's 10 short-period stations. Calculations of cross-correlation functions (CCFs) between pairs of stations were carried out following standard procedures, including mean and trend removal, band-pass filtering at different intervals, spectral whitening, and 1 bit normalization [Bensen et al., 2007]. Instrument responses were not removed because they were identical and constant in time at all stations. We calculated CCFs for delays ranging between $-150 \mathrm{~s}$ and $+150 \mathrm{~s}$. In most cases, they were calculated for the frequency interval [0.125-2] Hz and stacked over $24 \mathrm{~h}$. The CCFs for most station pairs were not symmetrical, which reflects the nonisotropic distribution of noise sources, most of which are located in the near Pacific Ocean (Figure 2). In our analyses, we generally used only one side of the CCFs, which gave more stable and reliable results. Furthermore, the CCFs calculated for pairs of stations on the volcano had more complex waveforms and more highly marked coda than those obtained outside the edifice. This reflects the heterogeneity and complexity of the volcanic structure. On the other hand, the CCFs showed a high degree of stability over the 15 year monitoring period (Figure 3), with correlation coefficients between CCFs stacked over 10 days being typically greater than 0.8 over the whole period (Figure 4). This stability allowed us to consider the CCFs as repeating similar seismograms and to use them to estimate velocity variations. 




Figure 4. Correlation matrix between the CCFs calculated over 15 years. Correlations were calculated for a delay range of $[-80-10] \mathrm{s}$, excluding Rayleigh waves, and a frequency interval of [0.125-2] Hz using 10 day stacks.
When velocity changes occur in the medium, the delays $\delta t$ they produce in the arrival of seismic waves increase with time in the seismograms, especially in the coda. The delays between a reference CCF and a current CCF were estimated using the stretching method, with one of the CCFs being stretched or compressed to obtain the best correlation $C_{\max }$ between the two CCFs [Lobkis and Weaver, 2003; Sens-Schönfelder and Wegler, 2006]. This procedure can be applied to various lag windows centered at a time lag $t$. The corresponding stretching coefficient $\varepsilon$ is equal to the relative delay time $\varepsilon=\delta t / t$. If the relative velocity variation is spatially homogeneous, it is equal to the negative of the relative delay time $\delta v / v=-\delta t / t=-\varepsilon$. Nevertheless, most velocity changes at Volcán de Colima are clearly localized, so the relative delay time depends on the time lag, and its relation with velocity changes is not simple. Therefore, we refer to the negative of the stretching coefficient as the Apparent Velocity Variation (AVV). We calculated errors in the relative delay time from $C_{\max }$ the frequency interval, and the lag window used [Weaver et al., 2011]. Errors were generally in the order of $0.01 \%$. When the correlation coefficient was smaller than 0.6 , the corresponding AVV was discarded.

We had to apply corrections for variations in the sampling frequency. Analog seismic signals from shortperiod seismometers are telemetered to the observatory where they are digitized by data acquisition boards with a common time reference. These boards have been replaced several times during the 15 years of continuous recording, which has resulted in variations in sampling frequency $F_{s}$ of up to $\pm 0.5 \mathrm{~Hz}$ around its nominal value of $100 \mathrm{~Hz}$. This has dilated or compressed the seismograms and generated spurious changes in arrival times. Figure 5 shows the relative variation in $F_{s}$ and the apparent velocity variations obtained by the stretching method. Part of these variations clearly appears to be due to changes in sampling frequency. This artifact has been corrected by subtraction.

\subsection{Results}

Figure 6a shows apparent relative velocity variations from 1998 to 2013 for the EZV5-EZV4 station pair, estimated using a large lag window in the seismic coda ( -80 to $-10 \mathrm{~s})$ and a broad frequency range $(0.125$ to $2 \mathrm{~Hz})$. This

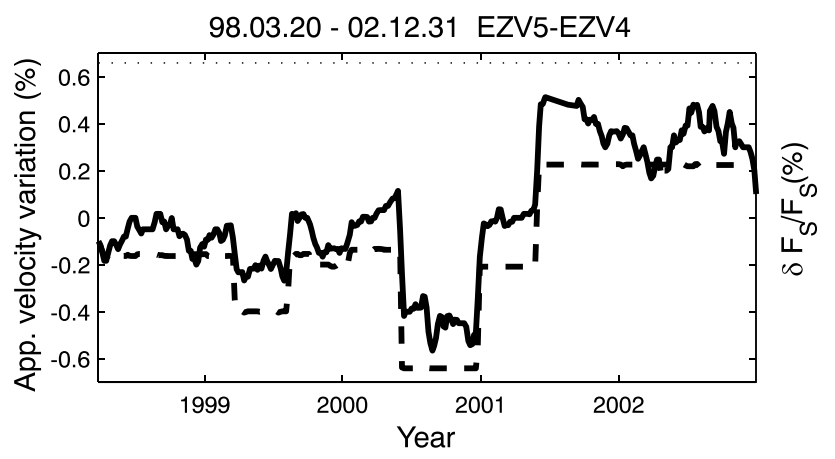

Figure 5. Relative variation (\%) in the acquisition board sampling frequency (dashed line) and apparent velocity variations (solid line) with no corrections. Part of the velocity variations appears to be an artifact of the nonconstant sampling frequency, which must be corrected by subtraction. pair of stations is located close to the crater and is the most sensitive to velocity perturbations. In this calculation we determined a reference cross-correlation function for these stations by stacking over the whole period. We obtained similar results for all pairs of stations on the volcano and when using other reference CCFs. Figure $6 \mathrm{~b}$ displays the corresponding values of $C_{\max }$ obtained during the stretching procedure and the error estimated using Weaver's formula. The graph in Figure 6a reveals numerous velocity changes over a variety of timescales. The relationship between these variations and explosive and extrusive 

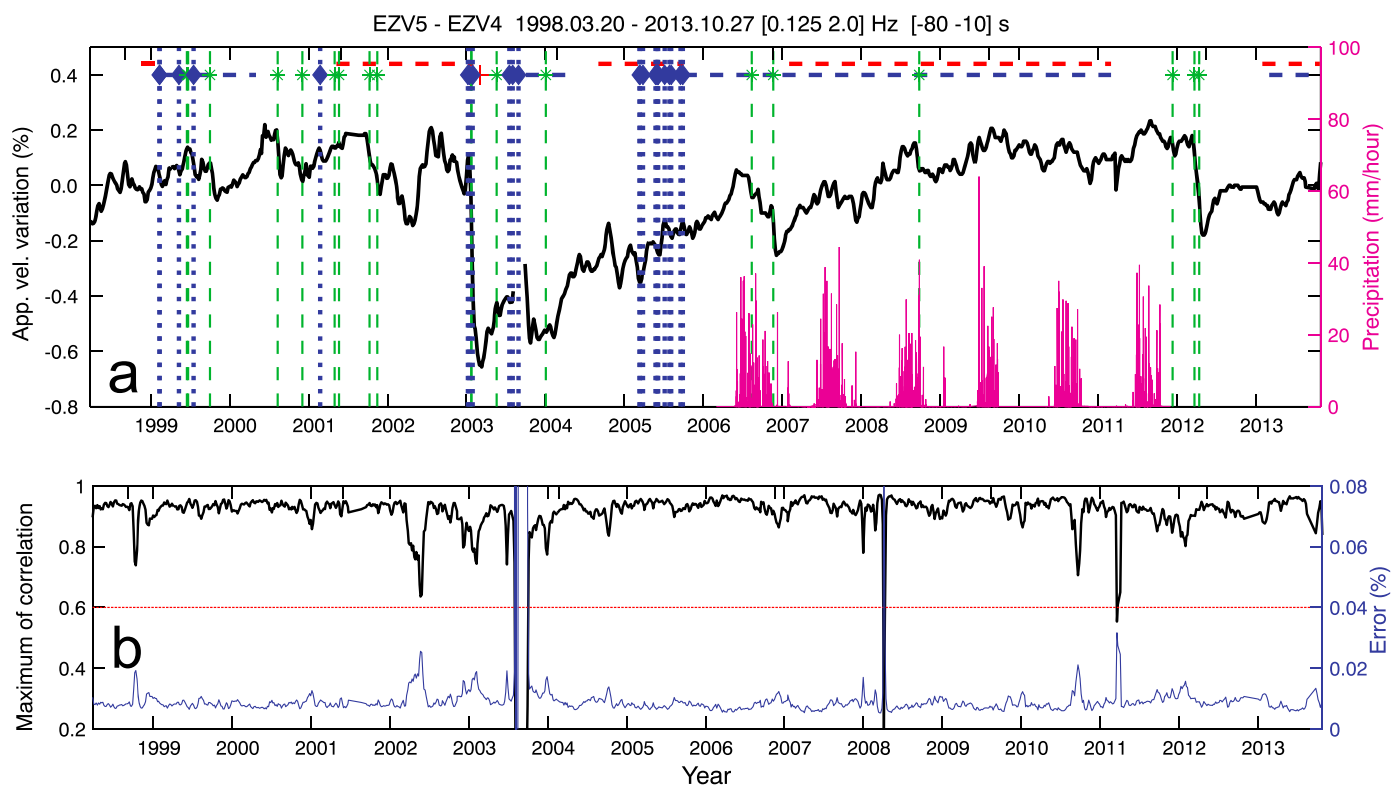

Figure 6. Apparent relative velocity variations obtained from cross correlations of ambient seismic noise. Station pair, dates, frequency ranges, and lag windows are given in the titles. Vertical, dashed green lines: tectonic earthquake $(M>6)$ less than $800 \mathrm{~km}$ from the volcano. Vertical, dotted blue lines: main vulcanian explosions. Horizontal, dashed blue lines: periods of explosive activity. Horizontal, dashed red lines: periods of magmatic extrusion. (a) Time series from 1998 to 2013, with CCFs stacked over 5 days. Hourly precipitation amounts (magenta) measured close to the volcano from 2006 to 2011. (b) Maximum correlation obtained by stretching (black) and error calculated on the apparent relative velocity variations (blue). Red dotted lines indicate a correlation threshold of 0.6 .
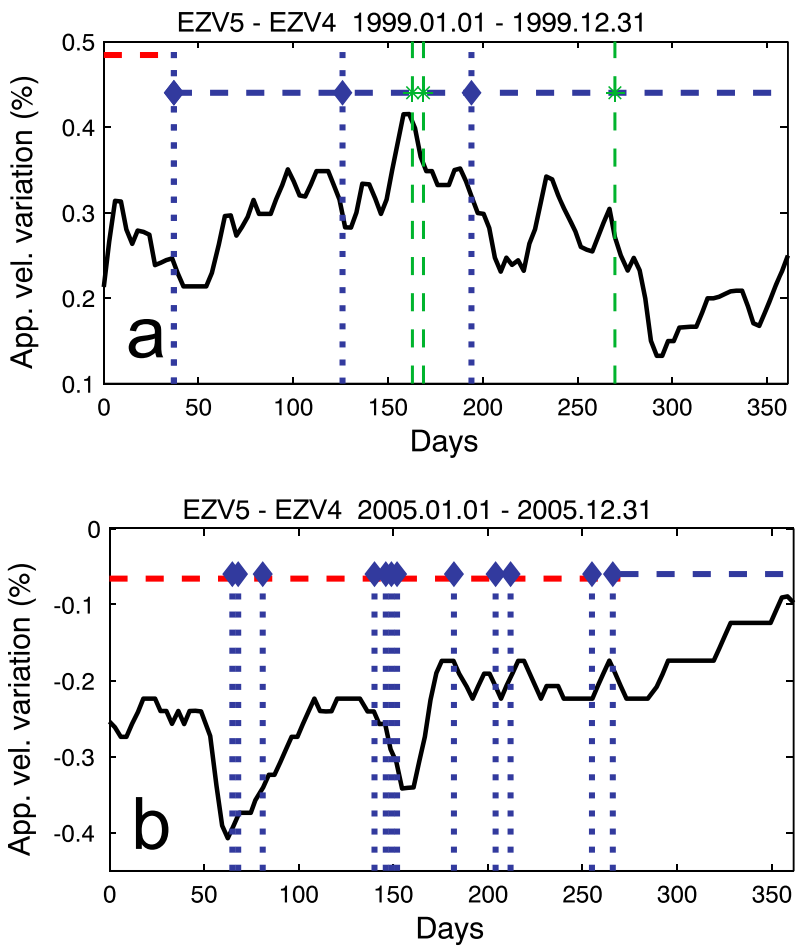

Figure 7. Same as Figure 6 but for periods of volcanic activity: (a) 1999, which included several tectonic earthquakes and vulcanian explosions and (b) 2005, which included the largest eruptive crisis in the last 15 years. activities is not clear; however, most of the vulcanian explosions appeared to occur when the seismic velocity was low or decreasing (Figure 7). We also noted weak seasonal velocity fluctuations with amplitudes of about $0.1 \%$. Stacks of velocity variations and precipitation amounts as a function of day of the year showed decreases in velocity during the rainy season (Figure 8 ). This effect is similar to that reported at Merapi volcano, Indonesia, and may be due to variations in the water table [Sens-Schönfelder and Wegler, 2006] or to an annual variation in the distribution of the noise sources.

The most striking feature in Figure $6 a$ is the sharp velocity decrease that occurred on 22 January 2003, during the M7.4 Tecomán earthquake. This thrust event was located in the subduction zone, at a depth of $20 \mathrm{~km}$ and $\sim 100 \mathrm{~km}$ from Volcán de Colima's crater [Yagi et al., 2004]. Calculations carried out with CCFs stacked over a mere $6 \mathrm{~h}$ indicate that the velocity decrease occurred within a shorter time than this period (Figure 9a). It is noteworthy that lava extrusion, which had begun in May 2001, 


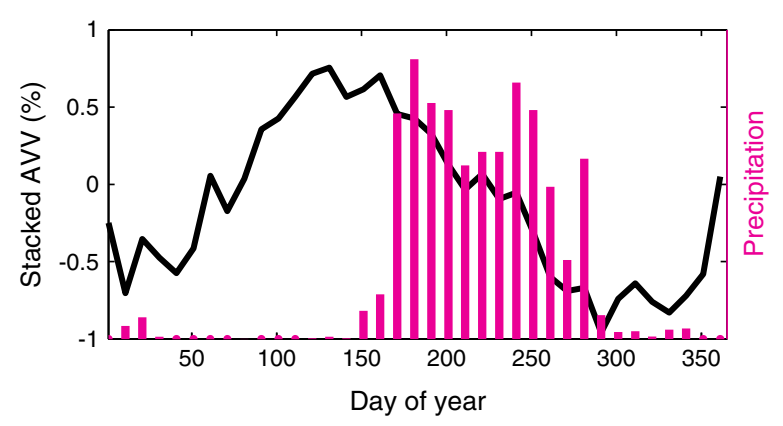

Figure 8. Stacks of apparent velocity variations (black line) and precipitation amounts (magenta) as a function of day of the year for 2006-2011.


Figure 9. Same as Figure 6 but for periods including large tectonic earthquakes. (a) Enlargement from 1 January to 5 February 2003, with CCFs stacked over $6 \mathrm{~h}$. The Tecomán earthquake and its main aftershock coincided with the largest velocity decrease. (b) AVVs calculated on six different pairs for 3 months around the Tecomán earthquake, with CCFs stacked over 1 day. (c) AVVs from 1 January 2011 to 31 October 2012, with CCFs stacked over 5 days. The occurrence of three earthquakes is shown by green lines. stopped 10 days after the earthquake. After this decrease, the velocity returned to its initial value over a period of approximately 5 years, although several episodes disrupted this recovery. Among the 26 earthquakes with magnitudes greater than 6 that occurred less than $800 \mathrm{~km}$ from the volcano during our 15 year study period, 15 events were associated with velocity decreases (Figure 1a). However, apart from the end of extrusion in 2003, mentioned above, they did not result in any clear modification in eruptive activity. The two largest velocity decreases (in 2003 and 2012) were followed by velocity recoveries that were almost linear with the logarithm of time for approximately 100 days after the associated earthquakes, until other perturbations occurred (Figure 10a). For the 15 earthquakes that induced velocity variations, all the shortperiod records and half of the broadband records from stations on the volcano were saturated because of the large amplitude of the surface waves and the monitoring stations that still require high gain in order to detect small seismovolcanic events. On the other hand, the broadband records of the large vulcanian explosions were never clipped, which indicates that the largest mechanical excitations of the edifice were caused by tectonic earthquakes, not by explosions. The level of saturation at the broadband station corresponds to a ground velocity of about $V_{0}=5 \times 10^{-3} \mathrm{~m} \mathrm{~s}^{-1}$. Assuming a rigidity $\mu=10^{10} \mathrm{~Pa}$ and a shear wave velocity $V_{S}=1700 \mathrm{~m} \mathrm{~s}^{-1}$, the corresponding amplitude of the dynamic stresses and strains can be estimated as $\sigma_{0}=\mu V_{0} / V_{S}=3 \times 10^{4} \mathrm{~Pa}$ and $\varepsilon_{0}=\sigma_{0} / \mu=3 \times 10^{-6}$, respectively. These values represent the lower bounds of the stresses and strains exerted on the shallow structure during the earthquakes. Because the amplitudes $A$ of the surface waves could not be retrieved from the clipped records, they were estimated from the corresponding magnitude $M_{S}=\log A / T+1.66 \log \Delta+3.3$, where $T$ is the dominant period and $\Delta$ the epicentral distance. Although these calculations are quite approximate, they showed that velocity variations were roughly proportional to the logarithm of the amplitude of the seismic waves that shook the volcano (Figure 10b). 



Figure 10. Features of velocity variations. (a) Velocity recoveries observed after the velocity decreases associated with the 2003 and 2012 earthquakes, as a function of the logarithm of time. Thin lines are logarithmic fits. (b) Absolute value of velocity decreases induced by tectonic earthquakes $(M>6$, distance $<800 \mathrm{~km})$ as a function of the corresponding surface wave amplitude (normalized by the amplitude of the Tecomán earthquake). Black diamonds show events that produced saturation of the broadband seismometer on the volcano.

\section{Location of Velocity Variations}

The size of the velocity decrease associated with the Tecomán earthquake was similar for all the pairs of stations on the volcano. It depended on the frequency range and the lag window used. The largest velocity decrease (2.6\%) was for the pair EZV5-EZV4, whose path crosses the volcanic cone, obtained using a lag window that included the ballistic surface waves (Figure 9a). Velocity decreases were smaller when one of the stations was not on the volcano, and smaller still for pairs of stations close to the coast and the epicenter (Figure 9b). These observations suggest that the velocity perturbations mostly affected the volcano. The location of the velocity perturbations within the structure can be determined using the spatial, frequential, and temporal behavior of the AVVs. To do this, we applied two complementary approaches: (1) mapping of velocity changes in the horizontal plane [Larose et al., 2010; Froment, 2011; Planès, 2013] and (2) estimation of the depth of the perturbations.

\subsection{Location in the Horizontal Plane}

We assumed that the coda of CCFs was composed of multiply scattered surface waves that propagate as a random walk process in a two-dimensional medium [Pacheco and Snieder, 2005] characterized by a transport mean free path $I^{*}$. A distribution of velocity perturbations $\delta v / v\left(\mathbf{x}_{0}\right)$ produces variations in the travel times as:

$$
\delta t(t)=-\int_{S} K\left(\mathbf{s}_{1}, \mathbf{s}_{2}, \mathbf{x}_{0}, t\right) \frac{\delta v}{v}\left(\mathbf{x}_{0}\right) \mathrm{d} S\left(\mathbf{x}_{0}\right)
$$

where $\mathbf{s}_{1}$ and $\mathbf{s}_{2}$ are the positions of the stations used to calculate the CCFs, $\mathbf{x}_{0}$ is the location of the perturbations, and $K$ is a sensitivity kernel given by the following:

$$
K\left(\mathbf{s}_{1}, \mathbf{s}_{2}, \mathbf{x}_{0}, t\right)=\frac{\int_{0}^{t} p\left(\mathbf{s}_{1}, \mathbf{x}_{0}, t^{\prime}\right) \cdot p\left(\mathbf{x}_{0}, \mathbf{s}_{2}, t-t^{\prime}\right) \mathrm{d} t^{\prime}}{p\left(\mathbf{s}_{1}, \mathbf{s}_{2}, t\right)} .
$$

The $p\left(\mathbf{s}_{1}, \mathbf{s}_{2}, t\right)$ represents the intensity of the wavefield between two points as a function of time [Pacheco and Snieder, 2005]. Here we used a solution of the radiative transfer equation in 2-D for the case of isotropic scatters [Shang and Gao, 1988; Sato, 1993; Paasschens, 1997; Planès, 2013]:

$$
p_{2-\mathrm{D}}^{\mathrm{RT}}(r, t)=\frac{1}{2 \pi r} \exp \left(-\frac{c t}{l}\right) \delta(c t-r)+\frac{1}{2 \pi / c t}\left(1-\frac{r^{2}}{c^{2} t^{2}}\right)^{-\frac{1}{2}} \cdot \exp \left[\frac{\sqrt{c^{2} t^{2}-r^{2}}-c t}{l}\right] \cdot \Theta(c t-r)
$$

where $l$ is the mean free path $\left(I=I^{*}\right.$ for isotropic scattering $), r$ is the distance between source and receiver, $c$ is the wave velocity, and $\Theta$ is the Heaviside function. This solution includes an exponentially decreasing term that represents the coherent part of the intensity and a term that describes the diffusion intensity. The sensitivity kernels $K\left(\mathbf{s}_{1}, \mathbf{s}_{2}, \mathbf{x}_{0}, t\right)$ depend on the distances between source, receiver, and the default, and on the time $t$ in the coda. They represent the time statistically spent in each elementary surface of the medium. The kernels have a saddle-like shape, with two sharp peaks at the source and receiver positions, and a ridge along the source-receiver axis (Figure 11). 

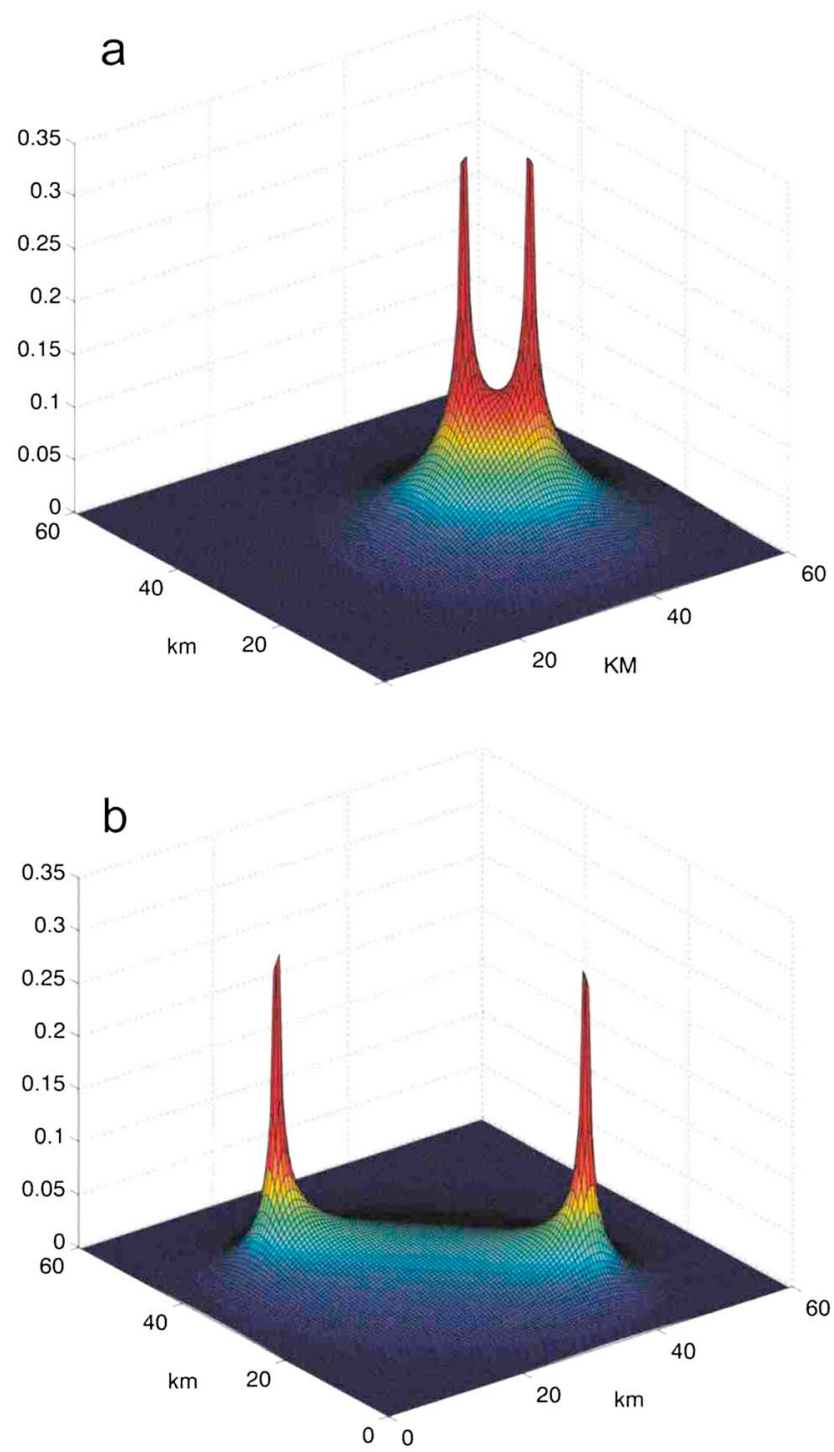

Figure 11. Examples of sensitivity kernel (equation (2)) based on the radiative transfer approximation in 2-D (equation (3)). Distances between source and receiver are (a) $8 \mathrm{~km}$ and (b) $37 \mathrm{~km}$. Other parameters used are mean free path $I=5 \mathrm{~km}$, wave velocity $c=2 \mathrm{~km} \mathrm{~s}^{-1}$, and time $t=50 \mathrm{~s}$.
Traveltime variations are related to the estimated stretching coefficients and apparent velocity variations:

$$
\begin{aligned}
\delta t(t) & =t \cdot \varepsilon(t)=-\left.t \cdot \frac{\delta v(t)}{v}\right|_{\mathrm{app}} \\
& =-\int_{S} K\left(\mathbf{s}_{1}, \mathbf{s}_{2}, \mathbf{x}_{0}, t\right) \frac{\delta v}{v}\left(\mathbf{x}_{0}\right) \mathrm{d} S\left(\mathbf{x}_{0}\right) .
\end{aligned}
$$

Thus, given a set of data, that is, AVVs or stretching coefficients obtained for different pairs of stations and different time lags in the CCFs, the distribution $\delta v / v\left(\mathbf{x}_{0}\right)$ can be estimated by solving equation (4) as a linear least squares inverse problem [Tarantola and Valette, 1982; Froment, 2011; Obermann et al., 2013b]. Equation (4) can be rewritten as follows:

$$
d=G \cdot m
$$

where $d$ is the data vector, whose components are the measured values of $-t \cdot \varepsilon(t), G$ is the matrix of the sensitivity kernels weighted by elementary surface, and $m$ is the model vector of the velocity perturbations $\delta v / v\left(\mathbf{x}_{0}\right)$. The stretching coefficients were evaluated between the CCFs stacked over the 50 days preceding the 22 January 2003 earthquake and the CCFs calculated for 10 to 20 days after the earthquake, depending on the stability over time of the AVVs. A total of 205 stretching coefficients from 27 pairs of stations were used as data in the inversion (Figure 13). The model covers an area of $115 \times 95 \mathrm{~km}$ and has a grid interval of $1 \mathrm{~km}$. A $20 \mathrm{~s}$ moving window with $10 \mathrm{~s}$ of overlap was used along the coda of CCFs. Time $t$ was defined as the center of the window. Only stretching coefficients that varied smoothly with time in the coda were used in the inversion. Because the problem is linear and the starting model of the perturbations is taken as null, the solution is given by the following:

$$
m=C_{m} G^{t}\left(G C_{m} G^{t}+C_{d}\right)^{-1} d
$$

where $C_{d}$ is the diagonal covariance matrix of the data and $G^{t}$ is the transpose of $G$. The covariance matrix of model $C_{m}$ is introduced in order to produce smooth models. In this study, we used a Sech-type function:

$$
C_{m}\left(\mathbf{s}_{1}, \mathbf{s}_{2}\right)=\left(\sigma_{m} \frac{\lambda_{0}}{\lambda}\right)^{2} \cdot \frac{1}{\operatorname{ch}\left(\frac{\left|\mathbf{s}_{1}-\mathbf{s}_{2}\right|}{\lambda}\right)}
$$

where $\lambda$ is the correlation length, $\lambda_{0}$ is the grid interval, and $\sigma_{m}$ is an a priori standard deviation. Using the $L$ curve criterion [Hansen, 1992], $\lambda$ and $\sigma_{m}$ were selected. With a grid spacing of $1 \mathrm{~km}$, we used values of $\lambda=5 \mathrm{~km}$ and $\sigma_{m}=0.002$.

The transfer mean free path $I^{*}$ can be estimated from the scattering quality factor $Q_{s}=2 \pi f I^{*} / V_{s}$, where $f$ is the frequency and $V_{s}$ the $S$ wave velocity. Values of $2 \mathrm{~km}$ at Masaya volcano, Nicaragua [Del Pezzo et al., 2001], $22 \mathrm{~km}$ 
a



b

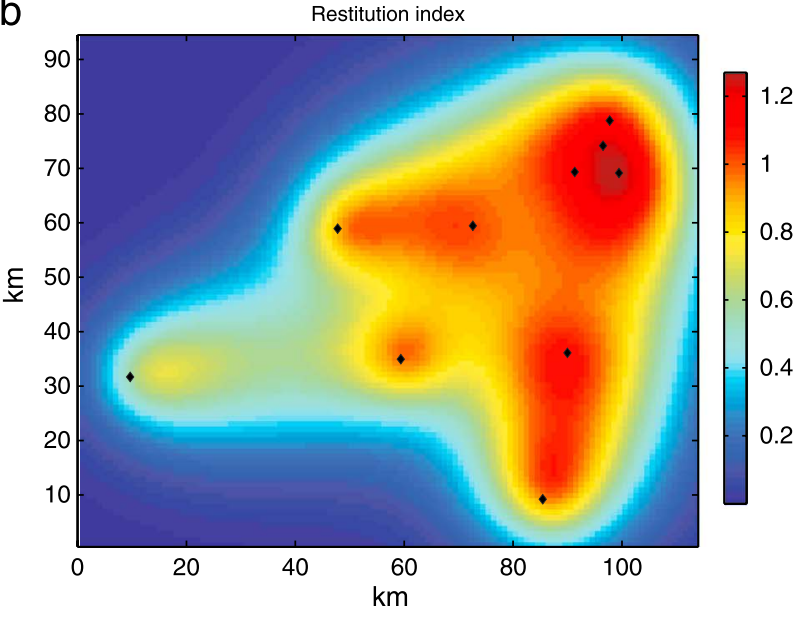

Figure 12. Location of the velocity perturbations associated with the 2003 Tecomán earthquake. (a) Map of velocity variations obtained by linear least squares inversion of the apparent velocity variations estimated for 27 pairs of stations (white lines) and various time lags. Red circle shows the crater position. (b) Map of corresponding restitution index. Velocities recovered well in regions where the restitution index is close to one. at Etna volcano, Italy [Del Pezzo et al., 2001], and $8 \mathrm{~km}$ on Hawaii [Mayeda et al., 1992] have been obtained using $V_{s}=1.2 \mathrm{~km} \mathrm{~s}^{-1}$. At Merapi volcano in Indonesia, values as low as $100 \mathrm{~m}$ have been estimated for the very shallow layers [Wegler and Lühr, 2001]. Recently, Prudencio et al. [2013a, 2013b] produced regional maps of the scattering quality factors at volcanoes on Tenerife and Deception Island. These maps show a large variability in $Q_{s}$ from which values of $I^{*}$ in the ranges [3-32] $\mathrm{km}$ and [220-1100] $\mathrm{m}$ were calculated for the two volcanoes, respectively. For the present research we chose a value of $5 \mathrm{~km}$, and we checked that the results of the inversion did not depend greatly on this value. This is consistent with the results reported by Rossetto et al. [2011], who demonstrated that this location method is not very sensitive to the value of the mean free path.

Figure $12 \mathrm{a}$ is a map of the velocity variations associated with the Tecomán earthquake in the region of Colima. It shows that the velocity perturbation was well localized within the volcano with almost no variation outside the edifice. After the sharp velocity decrease induced by the earthquake, the AVVs recovered their initial values with characteristic times that strongly depended on the pair of stations (Figure 9b). Therefore, it appears likely that the location of the perturbation changed with time during the recovery period. The fit between the model-calculated AVVs and the observations is quite good for most pairs of stations and time lags (Figure 13). The small number of discrepancies we found probably result from errors in the data, the inadequate distribution of the seismic stations, and the use of an oversimplified and smooth model that does not take into account the geological heterogeneity of the study region and, in particular, the variability of $I^{*}$ [Prudencio et al., 2013a, 2013b]. Nevertheless, the calculated AVVs are larger for pairs of stations located on the volcano (Figure 13a) than for stations far from it (Figure 13b). This is in line with the behavior of the observed AVVs.

The resolution matrix [Backus and Gilbert, 1967] is given by the following:

$$
R=C_{m} G^{t}\left(G C_{m} G^{t}+C_{d}\right)^{-1} G
$$

The sum of the elements of row $j$ of the matrix is the restitution index of the jth cell of the model [Vergely et al., 2010]. Figure $12 \mathrm{~b}$ is a map of the restitution index for all the cells. It shows that the index is generally larger than 0.8 inside the network, with values close to one on the volcano. Values close to one indicate good recovery of the velocity variations for the corresponding cell.

\subsection{Location in Depth}

The AVV estimated for a given pair and a given time lag depended on the frequency interval used to calculate the CCFs. For example, for pair EZV5-EZV4, whose path is close to the crater, the amplitude of the AVV produced by the Tecomán earthquake increased with frequency (Figure 14b). By assuming that 
a

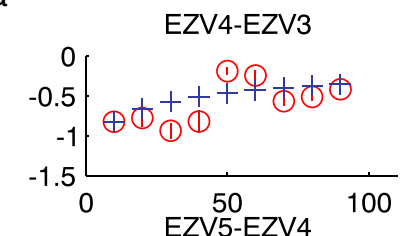

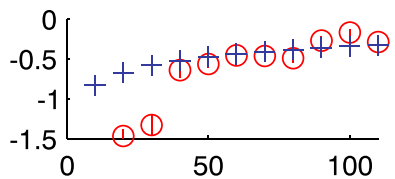

b
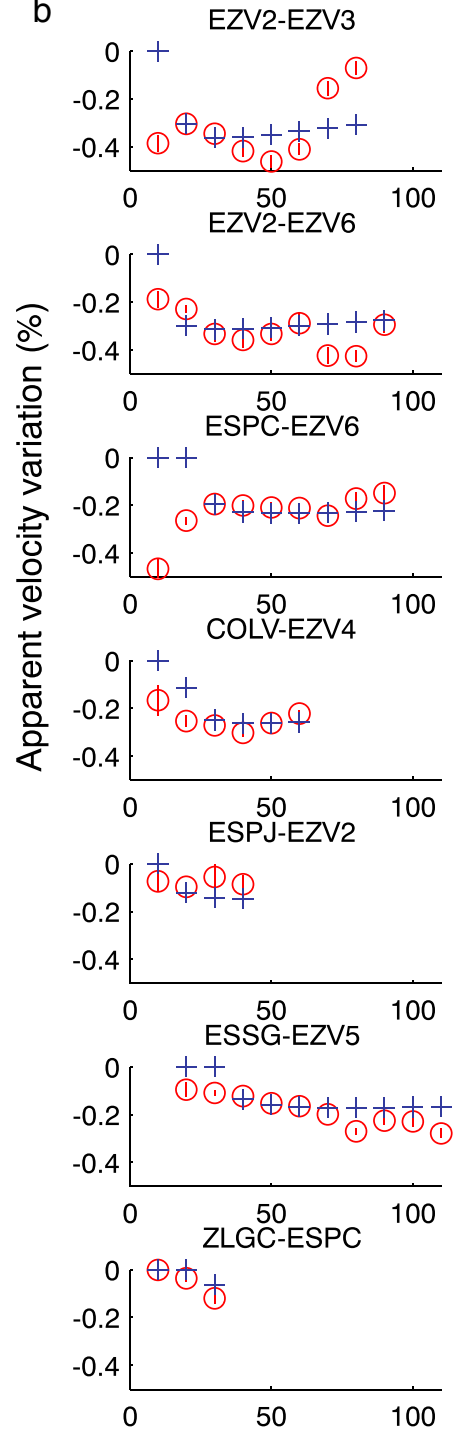
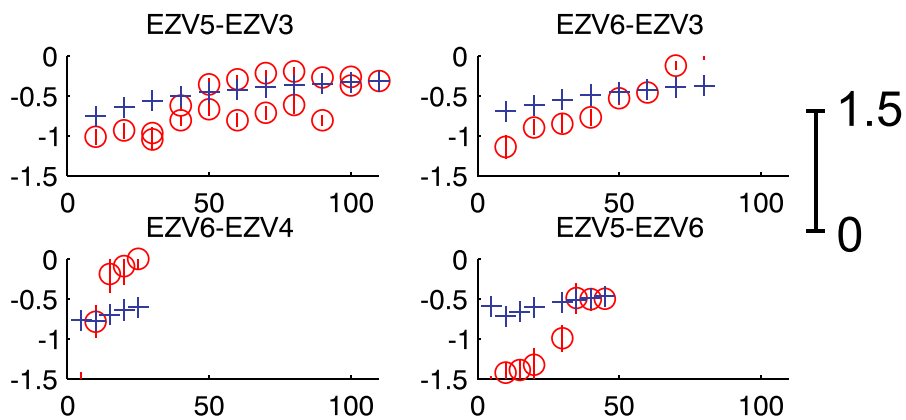

EZV2-EZV4
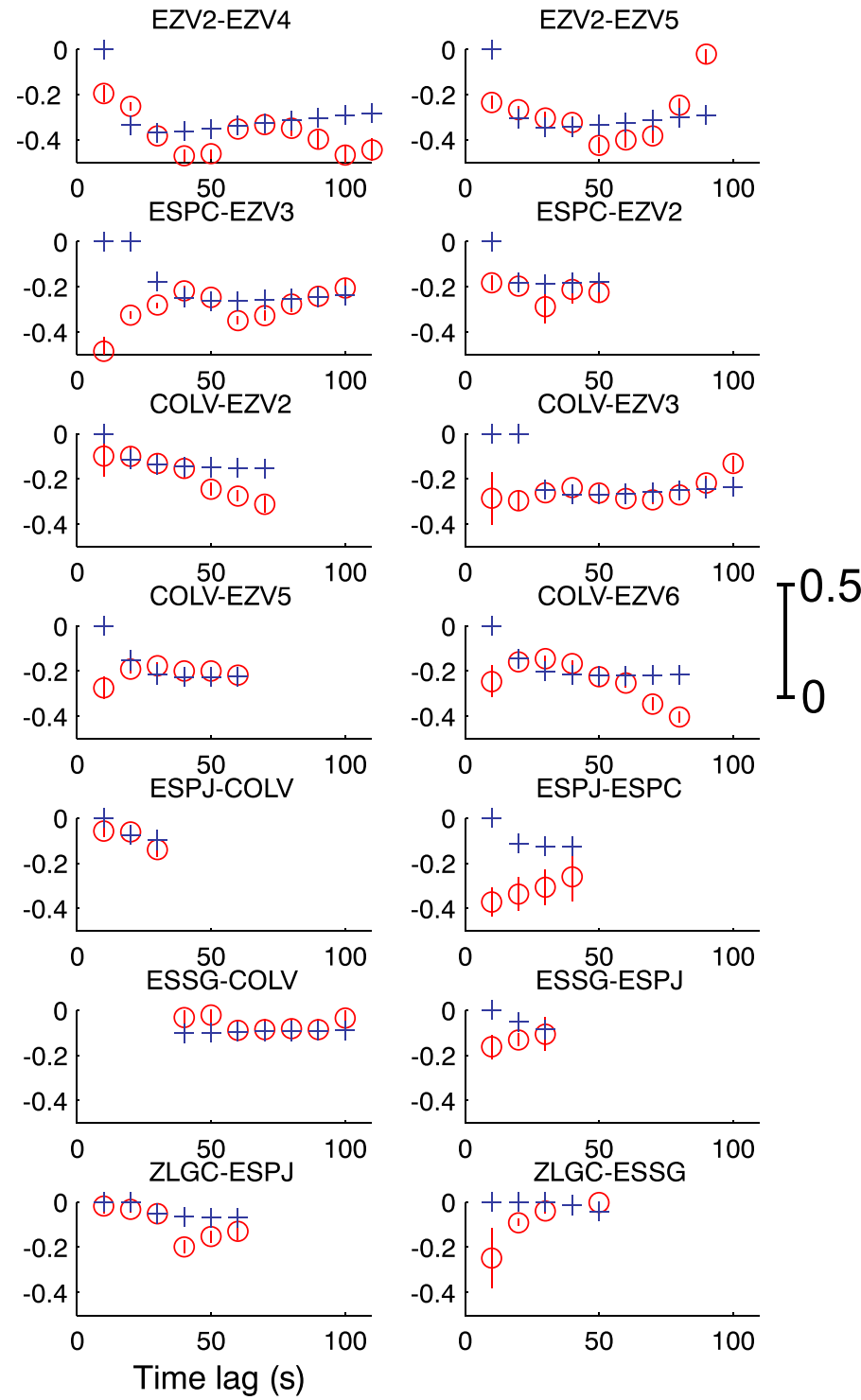

Figure 13. Apparent velocity variations as a function of time lag for the 27 pairs of stations used to locate the velocity perturbations in the 2-D structure. Open red circles show values estimated by the stretching method using 20 s overlapping delay windows in the [0.125-2] Hz frequency range. Uncertainties, shown by vertical bars, were calculated using Weaver et al.'s [2011] formula. Blue crosses are the values calculated using the model obtained by least squares inversion. (a) AVV for pairs of stations located on the volcano. For the pair EZV5-EZV3, AVV was estimated using both the causal and the acausal parts of the CCFs. (b) AVV for pairs with one or two stations outside the volcano. Because their amplitudes are much smaller, different scales are used in Figures 13a and 13b. 

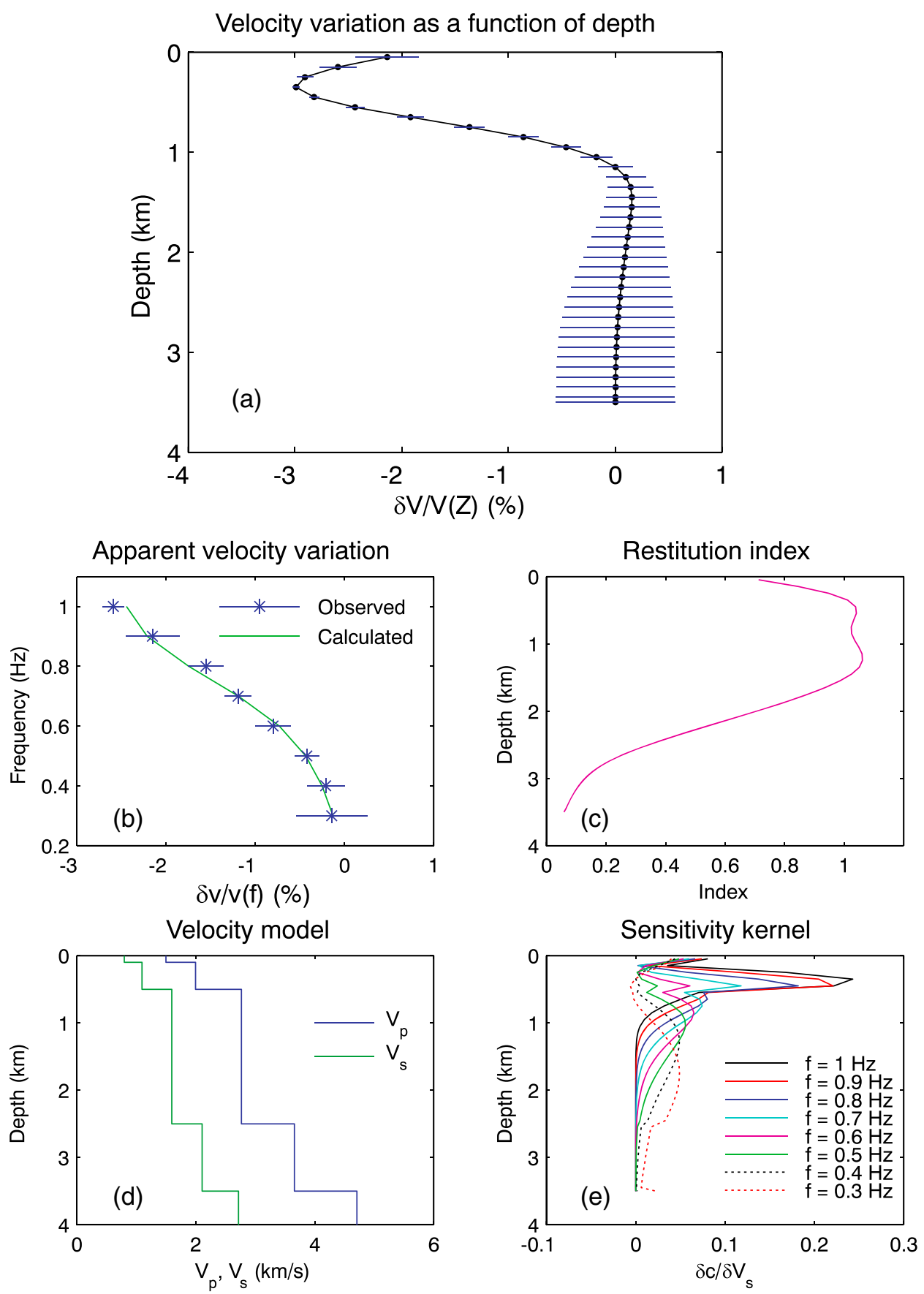

Figure 14. Distribution of the velocity perturbation associated with the Tecomán earthquake as a function of depth. The two CCFs used here were calculated for intervals of 50 and 20 days before and after the earthquake, respectively. (a) Velocity variations and error bars as a function of depth obtained by inverting apparent velocity variations calculated for different frequency ranges for the pair EZV5-EZV4. Velocity perturbations were concentrated in the volcanic structure at a depth of less than $800 \mathrm{~m}$. (b) Apparent velocity variations calculated as a function of frequency for the pair EZV5-EZV4 using lag window $[-60-30] \mathrm{s}$. AVVs (blue stars with error bars) were estimated using $0.2 \mathrm{~Hz}$ wide overlapping frequency intervals. The green line shows the AVVs calculated using the model shown in Figure 14a. (c) Restitution index showing that reliable information is retrieved up to $\sim 2 \mathrm{~km}$ depth. (d) Velocity model of the volcanic structure (adapted from ZamoraCamacho et al. [2007]). (e) Sensitivity kernels (derivatives of the phase velocity of Rayleigh waves with respect to $S$ wave velocity) for various frequencies. 
Rayleigh waves are dominant in the coda, the distribution in depth of the perturbation $\delta v / v(z)$ can be estimated from the relation

$$
\frac{\delta v}{v}(f)=\int K^{\text {depth }}(z, f) \frac{\delta v}{v}(z) \mathrm{d} z
$$

where $\delta v / v(f)$ is the AVV estimated for different frequency ranges and $K^{\text {depth }}(z, f)$ is a sensitivity kernel. For these kernels, we used the derivative of the Rayleigh wave phase velocity with respect to the $S$ wave velocity [Herrmann, 2004] (Figure 14e), calculated using the velocity model for Volcán de Colima published by ZamoraCamacho et al. [2007] (Figure 14d). The function $\delta v / v(z)$ is obtained by solving a linear least squares inverse problem similar to equation (6). The AVV as a function of frequency calculated using the resulting model fit the data very well (Figure 14b). Calculations of the restitution index during the inversion process [Vergely et al., 2010] gave values close to one up to $\sim 2 \mathrm{~km}$ depth, indicating that reliable results can be obtained in this interval (Figure 14c). These results show that most of the variations occurred at depths of less than $800 \mathrm{~m}$ (Figure 14a).

To conclude this section on location both in the horizontal plane and in depth, it is necessary to discuss our assumption that codas are dominated by surface waves. Actually, codas contain varying proportion of surface and body waves, due to the conversions that occur between the two types of wave in scattering media. Obermann et al. [2013a] addressed the issue of the sensitivity of coda waves to velocity perturbations at depth using numerical simulations. They demonstrated that at early times in the coda, waves most probably propagate as surface waves and are sensitive to shallow changes. Later in the coda, bulk waves dominate the depth sensitivity and offer the possibility of monitoring changes at larger depths. Obermann et al. also showed that with increasing lapse time, the AVV decreases for shallow perturbations and increases for deeper perturbations.

In the case of Colima, several arguments strengthen our assumption that surface waves are dominant:

1. For all six pairs of stations located on the volcano, the absolute value of AVV decreased when time lag increased (Figure 13), which is consistent with velocity changes close to the surface due to the dominant sensitivity of surface waves. The decreasing trend of $\varepsilon(t)$ could also result from the extension of the area sampled by the coda waves to regions where velocity perturbations were smaller than in the shallow volcano.

2. The wavelengths corresponding to the frequency range used $(0.125$ to $2 \mathrm{~Hz})$ are larger than the estimated depth of the perturbation; therefore, surface waves are sensitive to these shallow perturbations.

3. The seismic velocity increases rapidly with depth in the volcano (Figure 14d). This produces larger surface waves and these are dominant over a longer duration than in the case of the constant-background-velocity medium Obermann et al. [2013a] used in their simulations. Thus, the sensitivity to shallow perturbations associated with surface waves should be reinforced in the volcanic structure.

4. The increase in the absolute value of AVV with frequency is also consistent with our assumption.

However, part of the discrepancies between observed and calculated AVV (Figure 13) may result from the influence of body waves in the later part of the coda which was not taken into account in our approach. Further improvements of the location methods are required to better include velocity and scattering structures and varying sensitivity of surface and bulk waves with time lag and frequency.

\section{Discussion}

By calculating very long time series we were able to study long-term and short-term changes in seismic velocities in Volcán de Colima and detect, analyze, and interpret single and recurrent phenomena. Slight perturbations in seismic velocity were probably induced by meteorological phenomena with a dominant periodicity of 1 year. Eruptive activity had no marked impact on seismic velocity. The slight velocity decreases that coincided with vulcanian explosions in 1999 and 2005 may have resulted from the pressurization of the magmatic system which produced cracks openings in the solid structure [Ratdomopurbo and Poupinet, 1995; Nishimura et al., 2005; Brenguier et al., 2008; Mordret et al., 2010]. However, due to the open state of the conduit during the study period, no large strain variations could occur, at least not in the shallow layers $(<2 \mathrm{~km})$ where velocity variations could be detected. Recent detailed studies demonstrated complex patterns of AVV associated with eruptions, including simultaneous increases and decreases of velocity at different station pairs [Obermann et al., 2013b; Budi-Santoso, 2014]. Therefore, more realistic interpretations of these phenomena require physical modeling of the interaction between magmatic intrusion and surrounding medium. 
We found that large regional earthquakes produce sharp, temporary decreases in seismic velocities in Volcán de Colima. In particular, the Tecomán earthquake induced velocity variations that were well localized in the shallow layers of the volcano. Almost no variation was detected outside the edifice or at depth. The amplitude of the velocity variations increased with the amplitude of the corresponding seismic waves. After their sudden decrease, the velocities recovered almost linearly with the logarithm of time. These observations could be the result of a number of physical processes. Some authors have suggested that static stress changes can produce velocity variations due to the opening or closing of existing cracks related with stress changes [Ratdomopurbo and Poupinet, 1995; Nishimura et al., 2005]. However, the static stress fields associated with most of the earthquakes that struck the volcano were very small due to their large epicentral distances. In addition, this mechanism would have produced similar effects inside and outside the volcano, which was not the case at Volcán de Colima. Consequently, it is unlikely that this is the mechanism involved here, so we examined other processes associated with dynamic stresses.

The passing of seismic waves may produce perturbations in the magmatic system by triggering bubble growth, increasing the pressure, or propagating cracks. These processes should induce modifications in a volcano's eruptive state, especially in the case of an open system. Tectonic earthquakes did not produce any such changes at Volcán de Colima; therefore, it would appear unlikely that the recorded velocity variations were the result of magmatic processes. Earthquakes can also modify the permeability of the shallow crust, with strains as small as $10^{-6}$ being able to increase permeability by a factor of almost 10 [Elkhoury et al., 2006; Manga et al., 2012]. This effect is strongest with low-frequency waves. Permeability changes are thought to result from the mobilization of colloidal particles, droplets, or bubbles trapped in pores [Manga et al., 2012]. According to the Kozeny-Carman relationship, a $4.5 \%$ increase in permeability can increase the medium's porosity by $1 \%$. Moreover, poroelastic equations show that a $1 \%$ increase in porosity in this kind of saturated medium induces a decrease in shear wave velocity of about 0.6\% [Pride, 1994; Dupuy et al., 2011]. Therefore, decreases in velocity may be related to increases in permeability. However, the existence of a water table in Volcán de Colima has not been established, although there is probably a hydrothermal system at depth. In addition, once transient waves have cleared the pores and increased the permeability, further shaking will not produce another increase in permeability [Manga et al., 2012]. Consequently, this mechanism cannot explain the successive velocity decreases produced by two earthquakes that occurred within 22 days of each other in 2012 (Figure 9c), nor does it explain the fact that velocity perturbations occurred only inside the volcano and not outside it.

Another possible mechanism is material softening caused by seismic shaking [Guyer and Johnson, 1999; Johnson and Jia, 2005]. This effect is due to the nonlinear mesoscopic elastic behavior of the class of materials that includes rocks [Johnson and Sutin, 2005]. Laboratory experiments have shown that applying seismic strains to these materials decreases their elastic moduli. This softening is probably related to the nonlinear frictional properties of the contacts between the rigid grains of a granular material, or to the formation or growth of cracks [Guyer and Johnson, 1999]. Material softening is stronger in poorly consolidated rocks and is increased by the partial saturation of porous media [Van Den Abeele et al., 2002]. For example, apparent velocity decreases were observed following the 1989 Loma Prieta $M_{w} 6.9$ earthquake [Rubinstein and Beroza, 2004], with larger decreases at sites located on the youngest sedimentary rocks. Consequently, this mechanism, and the fact that volcanoes are composed of lava and have poorly compacted pyroclastic deposits near the surface, could explain why velocity variations are much larger at shallow depths in a volcano's structure. The elastic behavior of these granular pyroclastic deposits, which probably contain water, may be much less linear than the behavior of the rocks and sediments at depth and in the area around the volcano, especially those close to the coast. Furthermore, laboratory experiments have shown that the nonlinear behavior of rocks is effective over a strain threshold of the order of $10^{-6}$ and that the modulus of softening depends on wave duration and amplitude [Johnson and Jia, 2005; Johnson and Sutin, 2005]. The strains produced by the tectonic earthquakes at Volcán de Colima probably exceeded the nonlinearity threshold, as attested by the clipping of the seismic records. The sequence of two successive velocity decreases in 2012 is also consistent with the conditioning effect, which allows the modulus reductions associated with successive excitations to accumulate. In addition, the relationship between the amplitudes of seismic waves and the velocity decreases for the 15 events identified in the present study is consistent with the results of laboratory experiments. These experiments also reported velocity recoveries that follow a time logarithmic law. Such laws are characteristic of "slow dynamic" behaviors [Johnson and Sutin, 2005]. Similar behavior has been reported following earthquakes in California [Schaff and Beroza, 2004; Rubinstein and Beroza, 2004]. This large body of evidence suggests that the velocity decreases we observed in Volcán de Colima are best explained by the nonlinear, mesoscopic, elastic behavior of volcanic materials. 


\section{Conclusion}

During the 15 years of this study, seismic velocities in Volcán de Colima were affected by many phenomena of different origins. Small velocity variations were probably related to meteorological processes, such as the seepage of rain into the ground, or to changes in the distribution of noise sources in the ocean. Slight variations could also have been caused by volcanic activity. However, as they are mixed with other kinds of perturbation that may have had larger amplitudes, it would have been difficult to use these variations to predict the recent vulcanian explosions at this volcano. This is consistent with the low level of volcano-tectonic activity that preceded most of these eruptions. Such low-level activity would be associated with strain variations of too low amplitude, or affecting too small a volume in the structure, to have generated significant apparent velocity variations.

Our main finding is that large tectonic regional earthquakes were associated with sharp velocity decreases followed by slow velocity recoveries. The largest velocity variations were produced by the Tecomán earthquake and could be measured with good precision. We localized these velocity perturbations from their patterns in space, time, and frequency and found that they occurred in the shallow layers of the volcano, with almost no velocity variations occurring outside the structure. The good temporal resolution achieved for the apparent velocity variations in the volcano, with a sampling interval of only $6 \mathrm{~h}$, indicated that the velocity decreases probably occurred during the passing of seismic waves. This and other features of the phenomena suggest that the velocity decreases were the result of the softening of the poorly consolidated granular material that composes the shallow layers of the volcano. Such nonlinear behavior has been observed close to several tectonic faults but has never been reported so clearly in a volcano. Because the decrease in seismic velocity is the result of strong shaking of the ground, any sufficiently large explosion quake or volcano-tectonic event could also produce decreases. More observations and studies are needed to confirm this interpretation and evaluate its possible consequences.

\section{Acknowledgments}

We would like to thank M. Campillo, E. Larose, P. Roux, T. Planès, A. Obermann, S. Garambois, B. Valette, P. Johnson, and D. Legrand for helpful discussions, useful manuscripts, and programming elements. We are also grateful to Carlos Ariel Ramírez, Alejandro Velasquez Martinez, and Miguel González Amezcua, from RESCO, for their support in keeping the network working. J.-L. Got made constructive comments on the manuscript We thank the two reviewers for their useful suggestions. Some of this work was carried out during P.L.'s secondment to the Institute of Geophysics at the Universidad Nacional Autónoma de México, funded by the Institut de Recherche pour le Développement. It was partly supported by the ECOS-Nord program and the European Commission 6th Framework Project "VOLUME", contract 08471

\section{References}

Anggono, T., T. Nishimura, H. Sato, H. Ueda, and M. Ukawa (2012), Spatio-temporal changes in seismic velocity associated with the 2000 activity of Miyakejima volcano as inferred from cross-correlation analyses of ambient noise, J. Volcanol. Geotherm. Res., 247-248, 93-107.

Arámbula-Mendoza, R., P. Lesage, C. Valdés-González, N. R. Varley, G. Reyes-Davila, and C. Navarro (2011), Seismic activity that accompanied the effusive and explosive eruptions during the 2004-2005 period at Volcán de Colima, Mexico, J. Volcanol. Geotherm. Res., 205, 30-46, doi:10.1016/j.jvolgeores.2007.09.001.

Backus, G. E., and J. F. Gilbert (1967), Numerical applications of a formalism for geophysical inverse problems, J. R. Astron. Soc., 13, 247-276.

Barquero, R., P. Lesage, J.-P. Métaxian, A. Creusot-Eon, and M. Fernandez (1995), La crisis sísmica en el volcán Irazú en 1991 (Costa Rica), Rev. Geol. Amér. Cent., 18, 5-18.

Battaglia, J., J.-P. Métaxian, and E. Garaebiti (2012), Earthquake-volcano interaction imaged by coda wave interferometry, Geophys. Res. Lett., 39, L11309, doi:10.1029/2012GL052003.

Bensen, G. D., M. H. Ritzwoller, M. P. Barmin, A. L. Levshin, F. Lin, M. P. Moschetti, N. M. Shapiro, and Y. Yang (2007), Processing seismic ambient noise data to obtain reliable broad-band surface wave dispersion measurements, Geophys. J. Int., 169, 1239-1260.

Brenguier, F., N. M. Shapiro, M. Campillo, V. Ferrazzini, Z. Duputel, O. Coutant, and A. Nercessian (2008), Towards forecasting volcanic eruptions using seismic noise, Nat. Geosci., 1, 126-130, doi:10.1038/ngeo104.

Brenguier, F., D. Clarke, Y. Aoki, N. M. Shapiro, M. Campillo, and V. Ferrazzini (2011), Postseismic relaxation along the San Andreas Fault at Parkfield from continuous seismological observations, C. R. Geosci., 343, 633-638.

Budi-Santoso, A. (2014), The seismic activity associated with the large 2010 eruption of Merapi volcano, Java: Source location, velocity variation, and forecasting, PhD thesis. Univ. of Grenoble, Grenoble, France.

Campillo, M., and A. Paul (2003), Long-range correlations in the diffuse seismic coda, Science, 299, 547-549.

Cigolini, C., M. Laiolo, and D. Coppola (2007), Earthquake-volcano interactions detected from radon degassing at Stromboli (Italy), Earth Planet. Sci. Lett., 257, 511-525.

Clarke, D., L. Zaccarelli, N. Shapiro, and F. Brenguier (2011), Assessment of resolution and accuracy of the Moving Window Cross Spectral technique for monitoring crustal temporal variations using ambient seismic noise, Geophys. J. Int., 186, 867-882.

De la Cruz-Reyna, S. (1993), Random patterns of occurrence of explosive eruptions at Colima volcano, Mexico, J. Volcanol. Geotherm. Res., 55, 51-68.

Del Pezzo, E., F. Bianco, and G. Saccorotti (2001), Separation of intrinsic and scattering Q for volcanic tremor: An application to Etna and Masaya volcanoes, Geophys. Res. Lett., 28(16), 3083-3086, doi:10.1029/2001GL013372.

Dupuy, B., L. de Barros, S. Garambois, and J. Virieux (2011), Wave propagation in heterogeneous porous media formulated in the frequencyspace domain, Geophysics, 76(4), N13-N28.

Elkhoury, J. E., E. E. Brodsky, and D. C. Agnew (2006), Seismic waves increase permeability, Nature, 441(1), 135-138.

Froment, B. (2011), Utilisation du bruit sismique ambiant dans le suivi temporel de structures géologiques, PhD thesis, Univ. of Grenoble, Grenoble, France.

Gomberg, J., P. A. Reasenberg, P. Bodin, and R. A. Harris (2001), Earthquake triggering by seismic waves following the Landers and Hector Mine earthquakes, Nature, 411, 462-466.

Grêt, A., R. Snieder, R. C. Aster, and P. R. Kyle (2005), Monitoring rapid temporal change in a volcano with coda wave interferometry, Geophys. Res Lett., 32, L06304, doi:10.1029/2004GL021143.

Guyer, R. A., and P. A. Johnson (1999), Nonlinear mesoscopic elasticity: Evidence for a new class of materials, Phys. Today, $52,30-35$. 
Hansen, P. (1992), Analysis of discrete ill-posed problems by means of the L-curve, SIAM Rev., 34(4), 561-580. Herrmann, R. B. (2004), Computer programs in seismology, Source inversion, St. Louis Univ., St. Louis, Mo.

Hill, D. P., M. J. S. Johnston, and J. O. Langbein (1995), Response of Long Valley caldera to the Mw $=7.3$ Landers, California, earthquake,

J. Geophys. Res., 100, 12,985-13,005, doi:10.1029/95JB00860.

Johnson, P. A., and X. Jia (2005), Nonlinear dynamics, granular media and dynamic earthquake triggering, Nature, 437, 871-874.

Johnson, P. A., and A. Sutin (2005), Slow dynamics and anomalous nonlinear fast dynamics in diverse solids, J. Acoust. Soc. Am., 117(1), 124-130.

Lara, L. E., J. A. Naranjo, and H. Moreno (2004), Rhyodacitic fissure eruption in Southern Andes (Cordon Caulle; 40.5 degrees S) after the 1960 (Mw: 9.5) Chilean earthquake: A structural interpretation, J. Volcanol. Geotherm. Res., 138, 127-138.

Larose, E., T. Planes, V. Rossetto, and L. Margerin (2010), Locating a small change in a multiple scattering environment, Appl. Phys. Lett., 96(20), 204,101.

Linde, A. T., and I. S. Sacks (1998), Triggering of volcanic eruptions, Nature, 395, 888-890.

Lipman, P. W., J. P. Lockwood, R. T. Okamura, D. A. Swanson, and K. M. Yamashita (1985), Ground Deformation Associated With the Magnitude-7.2 Earthquake and Resulting Changes in Activity of Kilauea Volcano, Hawaii, 1975-1977, U.S. Geol. Surv. Prof. Pap., vol. 1276, 45 pp., U.S.G.S., Reston, Va.

Lobkis, O. I., and R. L. Weaver (2003), Coda-wave interferometry in finite solids: Recovery of P-to-S conversion rates in an elastodynamic billiard, Phys. Rev. Lett., 90(25), 254302.

Luhr, J. F., and I. S. E. Carmichael (1990), Petrological monitoring of cyclical eruptive activity at Volcán de Colima, México, J. Volcanol. Geotherm. Res., 42, 235-260.

Manga, M., and E. E. Brodsky (2006), Seismic triggering of eruptions in the Far field: Volcanoes and geysers, Annu. Rev. Earth Planet. Sci., 34, 263-291.

Manga, M., I. Beresnev, E. E. Brodsky, J. E. Elkhoury, D. Elsworth, S. E. Ingebritsen, D. C. Mays, and C.-Y. Wang (2012), Changes in permeability caused by transient stresses: Field observations, experiments, and mechanisms, Rev. Geophys., 50, RG2004, doi:10.1029/2011RG000382.

Marzocchi, W. (2002), Remote seismic influence on large explosive eruptions, J. Geophys. Res., 107(B1), 2018, doi:10.1029/2001JB000307.

Mayeda, K., S. Koyanagi, M. Hoshiba, K. Aki, and Y. Zeng (1992), A comparative study of scattering, intrinsic, and coda Q-1 for Hawaii, Long Valley, and central California between 1.5 and 15.0 Hz, J. Geophys. Res., 97, 6643-6659, doi:10.1029/91JB03094.

Medina-Martínez, F. (1983), Analysis of the eruptive history of the Volcán de Colima, México (1560-1980), Geofis. Int., 22, $157-178$.

Minato, S., T. Tsuji, S. Ohmi, and T. Matsuoka (2012), Monitoring seismic velocity change caused by the 2011 Tohoku-Oki earthquake using ambient noise records, Geophys. Res. Lett., 39, L09309, doi:10.1029/2012GL051405.

Moran, S. C., J. A. Power, S. D. Stihler, J. J. Sanchez, and J. Caplan-Auerbach (2004), Earthquake triggering at Alaskan volcanoes following the 3 November 2002 Denali fault earthquake, Bull. Seismol. Soc. Am., 94(6B), S300-S309.

Mordret, A., A. D. Jolly, Z. Duputel, and N. Fournier (2010), Monitoring of phreatic eruptions using interferometry on retrieved cross-correlation function from ambient seismic noise: Results from Mt. Ruapehu, New Zealand, J. Volcanol. Geotherm. Res., 191(1-2), 46-59.

Nakata, N., and R. Snieder (2011), Near-surface weakening in Japan after the 2011 Tohoku-Oki earthquake, Geophys. Res. Lett., 38, L17302, doi:10.1029/2011GL048800.

Nishimura, T., N. Uchida, H. Sato, M. Ohtake, S. Tanaka, and H. Hamaguchi (2000), Temporal changes of the crustal structure associated with the M6.1 earthquake on September 3, 1998, and the volcanic activity of Mount Iwate, Japan, Geophys. Res. Lett., 27(2), 269-272, doi:10.1029/1999GL005439.

Nishimura, T., S. Tanaka, T. Yamawaki, H. Yamamoto, T. Sano, M. Sato, H. Nakahara, N. Uchida, S. Hori, and H. Sato (2005), Temporal changes in seismic velocity of the crust around Iwate volcano, Japan, as inferred from analyses of repeated active seismic experiment data from 1998 to 2003, Earth Planets Space, 57(6), 491-505.

Norini, G., L. Capra, G. Groppelli, F. Agliardi, A. Pola, and A. Cortes (2010), Structural architecture of the Colima Volcanic Complex, J. Geophys. Res., 115, B12209, doi:10.1029/2010JB007649.

Obermann, A., T. Planes, E. Larose, C. Sens-Schönfelder, and M. Campillo (2013a), Depth sensitivity of seismic coda waves to velocity perturbations in an elastic heterogeneous medium, Geophys. J. Int., 194, 372-382.

Obermann, A., T. Planès, E. Larose, and M. Campillo (2013b), Imaging pre- and co-eruptive structural changes of a volcano with ambient seismic noise, J. Geophys. Res. Solid Earth, 118, 6285-6294, doi:10.1002/2013JB010399.

Paasschens, J. (1997), Solution of the time-dependent Boltzmann equation, Phys. Rev. E, 56(1), 1135.

Pacheco, C., and R. Snieder (2005), Time-lapse travel time change of multiple scattered acoustic waves, J. Acoust. Soc. Am., 118(3), 1300-1310.

Peng, Z., and Y. Ben-Zion (2006), Temporal changes of shallow seismic velocity around the Karadere-Düzce Branch of the North Anatolian fault and strong ground motion, Pure Appl. Geophys., 163, 567-600.

Planès, T. (2013), Imagerie de changements locaux en régime de diffusion multiple, PhD thesis, Univ. of Grenoble, Grenoble, France.

Poupinet, G., W. L. Ellsworth, and J. Fréchet (1984), Monitoring velocity variations in the crust using earthquake doublets: An application to the Calaveras fault, California, J. Geophys. Res., 89, 5719-5731, doi:10.1029/JB089iB07p05719.

Prejean, S., D. P. Hill, E. E. Brodsky, S. E. Hough, M. J. S. Johnston, D. Oppenheimer, M. Pitt, and K. Richard-Dinger (2004), Remotely triggered seismicity on the United States west coast following the M 7.9 Denali fault earthquake, Bull. Seismol. Soc. Am., 94, S358-S359.

Pride, S. R. (1994), Governing equations for the coupled electromagnetics and acoustics of porous media, Phys. Rev. B, 50, 15,678-15,696.

Pritchard, M. E., J. A. Jay, F. Aron, S. T. Henderson, and L. E. Lara (2013), Subsidence at southern Andes volcanoes induced by the 2010 Maule, Chile earthquake, Nat. Geosci., 6, 632-636.

Prudencio, J., E. Del Pezzo, A. García-Yeguas, and J. M. Ibáñez (2013a), Spatial distribution of intrinsic and scattering seismic attenuation in active volcanic islands-I: Model and the case of Tenerife Island, Geophys. J. Int., 195, 1942-1956.

Prudencio, J., J. M. Ibáñez, A. García-Yeguas, E. Del Pezzo, and A. M. Posadas (2013b), Spatial distribution of intrinsic and scattering seismic attenuation in active volcanic islands-II: Deception Island images, Geophys. J. Int., 195, 1957-1969.

Ratdomopurbo, A., and G. Poupinet (1995), Monitoring a temporal change of seismic velocity in a volcano: Application to the 1992 eruption of Mt. Merapi (Indonesia), Geophys. Res. Lett., 22(7), 775-778, doi:10.1029/95GL00302.

Rockstroh, E. (1902), Earthquake in Guatemala, Nature, 66, 150.

Rossetto, V., L. Margerin, T. Planes, and E. Larose (2011), Locating a weak change using diffuse waves: Theoretical approach and inversion procedure, J. Appl. Phys., 109(1), 034903.

Rubinstein, J. L., and G. C. Beroza (2004), Evidence for widespread nonlinear strong ground motion in the MW 6.9 Loma Prieta earthquake, Bull. Seismol. Soc. Am., 94(5), 1595-1608.

Rubinstein, J. L., N. Uchida, and G. C. Beroza (2007), Seismic velocity reductions caused by the 2003 Tokachi-Oki earthquake, J. Geophys. Res., 112, B05315, doi:10.1029/2006JB004440.

Sanchez, J. J., and S. R. McNutt (2004), Unexpected response of Mt. Wrangell volcano, Alaska, to the shaking from a large regional earthquake: A puzzle for intermediate-term earthquake-volcanoes interactions, Earth Sci. Res. J., 8(1), 34-44. 
Sato, H. (1993), Energy transportation in one- and two-dimensional scattering media: Analytic solutions of the multiple isotropic scattering model, Geophys. J. Int., 112, 141-146.

Schaff, D. P., and G. C. Beroza (2004), Coseismic and postseismic velocity changes measured by repeating earthquakes, J. Geophys. Res., 109, B10302, doi:10.1029/2004JB003011.

Sens-Schönfelder, C., and U. Wegler (2006), Passive image interferometry and seasonal variations of seismic velocities at Merapi volcano, Indonesia, Geophys. Res. Lett., 33, L21302, doi:10.1029/2006GL027797.

Shang, T., and L. Gao (1988), Transportation theory of multiple scattering and its application to seismic coda waves of impulsive source, Sci. Sin., 31, 1503-1514.

Takada, Y., and Y. Fukushima (2013), Volcanic subsidence triggered by the 2011 Tohoku earthquake in Japan, Nat. Geosci., 6, 637-641.

Tarantola, A., and B. Valette (1982), Generalized nonlinear inverse problems solved using the least squares criterion, Rev. Geophys. Space Phys., 28, 219-232.

Van Den Abeele, K. E.-A., J. Carmeliet, P. A. Johnson, and B. Zinszner (2002), Influence of water saturation on the nonlinear elastic mesoscopic response in Earth materials and the implications to the mechanism of nonlinearity, J. Geophys. Res., 107(B6), 2121, doi:10.1029/2001JB000368.

Vergely, J. L., B. Valette, R. Lallement, and S. Raimond (2010), Spatial distribution of interstellar dust in the Sun's vicinity-Comparison with neutral sodium-bearing gas, Astron. Astrophys., 518, A31.

Walter, T. R. (2007), How a tectonic earthquake may wake up volcanoes: Stress transfer during the 1996 earthquake-eruption sequence at the Karymsky Volcanic Group, Kamchatka, Earth Planet. Sci. Lett., 264, 347-359.

Walter, T. R., R. Wang, M. Zimmer, H. Grosser, B. Lühr, and A. Ratdomopurbo (2007), Volcanic activity influenced by tectonic earthquakes: Static and dynamic stress triggering at Mt. Merapi, Geophys. Res. Lett., 34, L05304, doi:10.1029/2006GL028710.

Weaver, R., and O. I. Lobkis (2001), Ultrasonics without a source: Thermal fluctuation correlations at MHz frequencies, Phys. Rev. Lett., $87(13), 134301$

Weaver, R. L., C. Hadziioannou, E. Larose, and M. Campillo (2011), On the precision of noise correlation interferometry, Geophys. J. Int., 185(3), 1384-1392.

Wegler, U., and B.-G. Lühr (2001), Scattering behaviour at Merapi volcano (Java) revealed from an active experiment, Geophys. J. Int., 145, 579-592.

Wegler, U., B.-G. Lühr, R. Snieder, and A. Ratdomopurbo (2006), Increase of shear wave velocity before the 1998 eruption of Merapi volcano (Indonesia), Geophys. Res. Lett., 33, L09303, doi:10.1029/2006GL025928.

West, M., J. J. Sanchez, and S. McNutt (2005), Periodically triggered seismicity at Mount Wrangell, Alaska, after the Sumatra earthquake, Science, 308, 1144-1146.

Yagi, Y., T. Mikumo, J. Pacheco, and G. Reyes (2004), Source rupture process of the Tecomán, Colima, Mexico earthquake of 22 January 2003 , determined by joint inversion of teleseismic body-wave and near-source data, Bull. Seismol. Soc. Am., 94(5), $1795-1807$.

Zamora-Camacho, A., J. M. Espindola, and G. Reyes-Davila (2007), The 1997-1998 activity of Volcán de Colima, western Mexico: Some aspects of the associated seismic activity, Pure Appl. Geophys., 164(1), 39-52. 